\title{
Has Monetary Policy Been More Accomodative Than Previously Believed?
}

\section{Kevin L. Kliesen}

S ince their January 30, 2002, meeting, the Federal Open Market Committee (FOMC) has routinely characterized its monetary policy stance as "accommodative." A commonplace interpretation of such a policy is one in which the FOMC's intended federal funds rate is kept at a level that, over time, is expected to support faster growth of aggregate demand (estimates of real GDP) relative to aggregate supply (estimates of potential GDP). If sustained for too long, an accommodative policy can become destabilizing, creating inflationary conditions.

One of the challenges of this sort of policy is that the data policymakers base their decisions on are subject to revision. For example, the national income and product accounts (NIPA) data are revised annually. These revisions include both quantity measures (real GDP and components and incomes and profits, etc.) and associated price indexes (including the "core" personal consumption expenditures $[\mathrm{PCE}]$ price index, which the FOMC tends to focus on). Typically these "benchmark" revisions cover three years and sometimes incorporate changes in methodology; however, once every five years or so, the Bureau of Economic Analysis (BEA) undertakes a more comprehensive revision, which can alter the economic picture going back much further. The latest benchmark revision was released by the BEA on July 29, 2005.

The most interesting aspect of this year's revisions was the upward revision to the major price indexes. Growth of the GDP price index over the three-year period was raised from 2 percent to 2.3 percent, while the PCE price inflation rate over the revision period was boosted from 2 percent to 2.2 percent.

Since the July 2004 Monetary Policy Report to the Congress, FOMC policymakers have chosen to emphasize the PCE inflation rate that excludes food and energy prices (core PCE). Although the core PCE price index was revised upward by only about 0.25 percentage points to about 1.75 percent over the three-year period, what is perhaps worrisome is that the largest revisions to the core PCE inflation rate have occurred since mid-2003. This is the period when monetary policy was character- ized as accommodative and economic growth was generally robust. From 2003:Q2 to 2005:Q1, the annualized growth rate of the core PCE price index was revised up 0.5 percentage points to 2 percent.

One implication of these data revisions is that monetary policy now appears to have been more accommodative than what the FOMC believed at the time. As seen in the figure, the ex-post inflation-adjusted federal funds target rate (nominal funds rate less the 12-month change in the core PCE) became even more negative in 2004, whereas in real time the target rate was observed to have risen to slightly above zero. ${ }^{1}$ In fact, current estimates show that a negative real federal funds rate persisted until the December 2004 meeting, probably a more stimulative stance than the FOMC intended. While the policy implications of this particular data revision may not be large, it nevertheless reinforces the difficulties that FOMC policymakers confront when implementing policy in real-time.

\footnotetext{
${ }^{1}$ The real-time estimates of the core PCE inflation rate are reported in the monthly personal income and expenditure reports archived on the BEA's website (www.bea.gov). The estimates are the 12-month inflation rates that policymakers confronted at that particular meeting.
}

\section{Real Federal Funds Target Rate: Before and After the July 2005 NIPA Revisions}

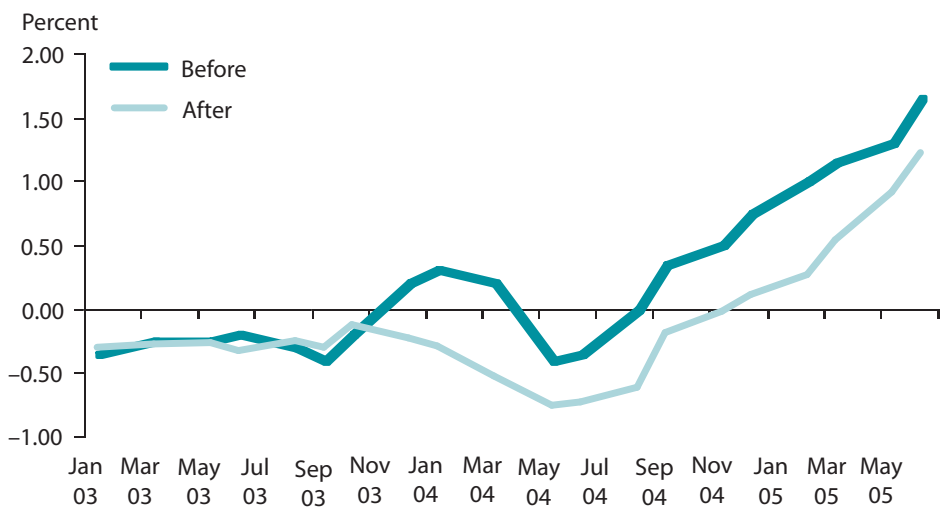

